standardised approach to blood transfusion documentation, highlighting indication for blood transfusion, consent and desired outcome achieved. Our aim with this audit was to assess completion of the blood booklet and identify areas for improvement.

Method A retrospective audit of the completion of the blood transfusion booklet within the neonatal unit in Craigavon Area Hospital was carried out. This was for all blood transfusions between October and December 2010.

Results 9 babies and 11 transfusion episodes were included. 3/9 babies were $25-30$ weeks gestation, 4/9 babies were 1001-1500g. 4 of the transfusion episodes were classified as emergency transfusions. 1 adverse incident occurred during the audit period. Clinical observations were documented in 11 cases, consent in 9/11 cases. The main concerns were regarding blood prescription as special requirements, volume of blood and rate of transfusion were not documented adequately.

Conclusion This highlighted a need to improve the prescribing of blood products. The prescription chart was revised to include a column for volume and duration of transfusion in millilitres/ hour. A specific blood transfusion booklet provides a readily available record of transfusions given and clear guidance for indication and prescribing of blood products. Our hope is that this will consequently result in safer blood transfusion practice.

\section{SURVEY ON THRESHOLD FOR PACKED RED CELL TRANSFUSION IN NEONATAL UNITS ACROSS THE UK}

doi:10.1136/archdischild-2012-302724.0255

'V Satwik, 2J Cyriac. 'Paediatric Cardiology, Southampton General Hospital, Southampton; 'Paediatrics, Broomfield Hospital, Mid Essex Hospitals NHS Trust, Chelmsford, UK

Aim Neonatal blood-product transfusion practices and policies vary widely among different institutions. The aim of this survey was to evaluate the threshold for packed red cell (PRC) transfusion for non-haemolytic neonatal anaemia in neonatal units across the UK.

Methods Data regarding the threshold for PRC transfusion in neonatal units was collected by means of telephone conversation. The number of units called was random and the first 100 units to provide full details were regarded as end point. Data was collected from April 2010 to August 2010.

Results Of the 100 units surveyed, $46 \%$ were level II units (46/100), $32 \%$ were level III $(32 / 100)$ and $22 \%(22 / 100)$ were level I units. Eight units did not have a documented transfusion policy (4 level I and 4 level II). The range of transfusion thresholds between the units is shown in Figure 1 and the most commonly used transfusion thresholds (TT) is shown Figure 2

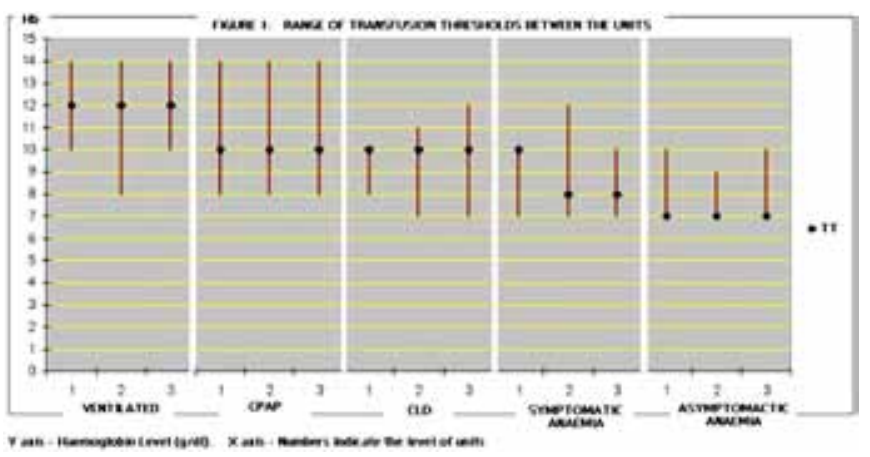

Abstract 255 Figure 1

\begin{tabular}{|c|c|c|c|c|c|c|}
\hline \multicolumn{7}{|c|}{ Figure 2: Most commonly used thresholds of $\mathrm{Hbx}$} \\
\hline \multirow[b]{2}{*}{ Invasive ventilation } & \multicolumn{2}{|c|}{ Level $1(n=18)$} & \multicolumn{2}{|c|}{ Level $2(n=42)$} & \multicolumn{2}{|c|}{ Lever $3(n=32)$} \\
\hline & $<12$ & $(8 / 18)$ & $<12$ & $(28442)$ & $<12$ & $(14 / 32)$ \\
\hline CPAP & $<10$ & $(7 / 18)$ & $<10$ & $(17 / 42)$ & $<10$ & $(11 / 32)$ \\
\hline $\begin{array}{l}\text { Chronic lung disease } \\
\text { (CD) }\end{array}$ & $<10$ & (818) & $<10$ & $(17 / 42)$ & $<10$ & $(1032)$ \\
\hline Symptomatic anaemia & $<10$ & $(4 / 18)$ & 28 & $(11 / 42)$ & $<8$ & $(1032)$ \\
\hline $\begin{array}{l}\text { Asymptomatic } \\
\text { gnaemia }\end{array}$ & & $(7 / 18)$ & $<7$ & $(28 / 42)$ & $<7$ & $(21 / 32)$ \\
\hline
\end{tabular}

Abstract 255 Figure 2 Most commonly used thresholds of $\mathrm{Hb}$

Discussion There was wide variation in threshold for PRC transfusion across the units we surveyed. Some units did not have a transfusion policy. A national guideline based on consensus and evidence is recommended to ensure homogeneity in clinical practice between units. This will also be useful in auditing, ensure accountability and cost effective practice.

\section{MUTATIONS IN THE G6PD AND UGT1A1 GENES ASSOCIATED WITH SIGNIFICANT HYPERBILIRUBINAEMIA IN ASIAN NEWBORN INFANTS}

doi:10.1136/archdischild-2012-302724.0256

${ }^{1} \mathrm{FC}$ Cheah, ${ }^{1,2} \mathrm{FL}$ Wong, ${ }^{1} \mathrm{SK}$ Chow, ${ }^{2} \mathrm{~A}$ Ithnin, ${ }^{2} \mathrm{~A}$ Othman. ${ }^{1}$ Paediatrics; ${ }^{2}$ Pathology, Universiti Kebangsaan Malaysia Medical Centre, Kuala Lumpur, Malaysia

Background and Aims The G6PD gene mutation is associated with the development of neonatal hyperbilirubinaemia in Asian infants. The c.211G>A mutation of the UGT1A1 gene may contribute but the clinical significance and impact of a combination of these mutations have not been explored. The purpose of this study was to determine whether G6PD and UGT1A1 mutations together, were associated with significant neonatal hyperbilirubinaemia.

Methods Venous blood samples were collected from newborn infants monitored for jaundice and from non-jaundiced infants who served as controls. The G6PD and c. 211G $>$ A of UGT1A1 gene mutations commonly reported among Asians were studied. G6PD enzyme measurements were performed using the fluorescent spot test and enzyme activity assay. Significant hyperbilirubinaemia was defined as a total serum bilirubin (TSB) of $\geq 250 \mu \mathrm{mol} / \mathrm{L}$.

Results The majority of infants were of Malay $(n=256)$ and Chinese $(\mathrm{n}=89)$ descent. The G6PD mutations obtained were c.871G $>A$ (17.4\%), c.487G>A (6.3\%), c.1376G>T (4\%) and c.1388G>A (3\%). One in five infants with G6PD deficiency developed significant hyperbilirubinaemia at three days of life. Infants with c.211G>A of UGT1A1 (18.8\%) were two times more likely to be associated with significant hyperbilirubinaemia $(p=0.026)$. Even if normal G6PD, the mean TSB among heterozygous/homozygous c.211G>A mutation $(291 \pm 78 \mu \mathrm{mol} / \mathrm{L})$ was significantly higher than normal UGT1A1 $(241 \pm 73 \mu \mathrm{mol} / \mathrm{L})(\mathrm{p}=0.014)$. The limited number of infants showing combined G6PD and UGT1A1 mutations did not impact significantly on hyperbilirubinaemia in this study.

Conclusion c.211G $>$ A UGT1A1 mutation was an independent risk factor, with c.871G>A being the most common G6PD mutation associated with significant hyperbilirubinaemia amongst Malaysian neonates.

\section{THE SAFETY AND EFFICACY OF RED CELL TRANSFUSIONS IN NEONATES: A SYSTEMATIC REVIEW OF RANDOMISED CONTROLLED TRIALS}

doi:10.1136/archdischild-2012-302724.0257

'V Venkatesh, 'R Khan, ${ }^{1} \mathrm{~A}$ Curley, ${ }^{2} \mathrm{C}$ Doree, ${ }^{3} \mathrm{~S}$ Hopewell, ${ }^{2} \mathrm{~S}$ Stanworth. ${ }^{1} \mathrm{NICU}$ Cambridge University Hospitals NHS Foundation Trust, Cambridge; ${ }^{2}$ Haematology; ${ }^{3} \mathrm{SRI}$, NHSBT, Oxford, UK 